\title{
Fuzzy Logic in Business, Management and Accounting
}

\author{
Alexander Báez Hernández¹, Debrayan Bravo Hidalgo² \\ ${ }^{1}$ Administrative Sciences Department, Universidad Central del Ecuador, Quito, Ecuador \\ ${ }^{2}$ Sharing Knowledge Group (SKG), Quito, Ecuador \\ Email: albaez@uce.edu.ec, dbrayanbh@gmail.com
}

How to cite this paper: Hernández, A. B. \& Hidalgo, D. B. (2020). Fuzzy Logic in Business, Management and Accounting. Open Journal of Business and Management, 8 , 2524-2544.

https://doi.org/10.4236/ojbm.2020.86157

Received: October 5, 2020

Accepted: November 14, 2020

Published: November 17, 2020

Copyright (๑) 2020 by author(s) and Scientific Research Publishing Inc. This work is licensed under the Creative Commons Attribution International License (CC BY 4.0).

http://creativecommons.org/licenses/by/4.0/

\section{(c) (i) Open Access}

\begin{abstract}
The aim of the paper is to show the implementation of fuzzy logic in business, administration and accounting, through the research published in Scopus. The results of the document focus on the following sections: 1) Fuzzy set theory, in business, administration and accounting. 2) Analysis of fuzzy logic bibliometrics in business, administration and accounting. 3) Identification and characterization of the documents or seminal documents most cited in applications of fuzzy logic in business, administration and accounting. The method used in this contribution is documentary research using the Scopus database and the VOSviewer science bibliometric analysis and mapping tool. In the future, this computational practice will focus on new diffuse models and the combination of these with other artificial intelligence techniques such as neural networks, genetic algorism, forage bacteria, among others.
\end{abstract}

\section{Keywords}

Artificial Intelligence, Decision Making, Management Tools, Accounting Operations

\section{Introduction}

The fuzzy logic appears for the first time in the mid-60s of the twentieth century and since then, the theoretical contributions and the development of its applications have continued to be considered today one of the most used artificial intelligence techniques (Díaz Córdova, Coba Molina, \& Navarrete, 2017; Kokles, Filanová, \& Korček, 2016; Ouahli \& Cherkaoui, 2019). To a certain extent, the diffuse logic is based on the observation of human behavior, where despite the knowledge of man is faced with many imperfect situations and has certain uncertainties and inaccuracies, his decisions are correct (Díaz Córdova et al., 2017; 
Dostál \& Lin, 2018; Dostál, Rukovanský, \& Králik, 2018; Kokles et al., 2016; Ouahli \& Cherkaoui, 2019; Pislaru, Alexa, \& Avasilcăi, 2018; Plessis, Martin, Roman, \& Slabbert, 2018); that is to say: the solution of complex problems solves them with the help of approximate data which indicates that the precision is often unnecessary. In this way, any activity does not require an exact and rigorous mathematical model, as it has not been for driving a vehicle or deciding when a bank grants a loan to a client, although it is known that these are complex issues that require above all skills and knowledge. In addition to being acquired through self-effort, they are obtained through experience (Díaz Córdova et al., 2017; Dostál \& Lin, 2018; Dostál et al., 2018; Grekousis, Manetos, \& Photis, 2013; Kokles et al., 2016; Morano, Locurcio, Tajani, \& Guarini, 2015; Osiro, Lima-Junior, \& Carpinetti, 2014; Ouahli \& Cherkaoui, 2019; Pislaru et al., 2018; Plessis et al., 2018). Fuzzy logic deals with the usefulness of imprecision and the relative importance of precision (Bolloju, 1996; Chakraborty, Ravi, Shivangi, Vanshika, \& Vishal, 2019; Halabi \& Shaout, 2019; Levy, Mallach, \& Duchessi, 1991).

From this premise, it can be inferred that the diffuse logic to provide a solution needs a human know-how. Diffuse logic can consider variables of a qualitative nature that are hardly recognized by other techniques and provides an effective approach by systematizing the empirical terrain and transcribing and giving dynamism to experts' knowledge (Dostál et al., 2018; Sharma \& Saxena, 2017). This universal aspect of fuzzy logic allows to apply it in business decision making, negotiation management and commerce processes, based mainly on the experience gained in the management of processes where classical systems have limited behavior (Almutairi, Salonitis, \& Al-Ashaab, 2019; Chao \& Liaw, 2019).

Fuzzy logic is currently used in a large number of processes, such as financial analysis software, control of energy management systems, validation of electoral processes, medical instruments and in many other applications (Al Nahyan, Hawas, Aljassmi, \& Maraqa, 2018; Djekic, Smigic, Glavan, Miocinovic, \& Tomasevic, 2018; Sivamani, Kim, Park, \& Cho, 2017). The advantage of the combination of artificial intelligence techniques such as fuzzy logic, neural networks, bacteria fodder and genetic algorithms is that they provide effective solutions in a large number of applications and with a low cost of time and resources (Knight \& Fayek, 2002; Kunsch \& Vander Straeten, 2015; Kushwaha \& Suryakant, 2014; Mujahid \& Duffuaa, 2007). Artificial intelligence tools such as Fuzzy Logic have been successfully used in energy and resource management (Bravo Hidalgo, 2015; Bravo Hidalgo \& León González, 2018; Hidalgo \& Guerra, 2016).

The fundamental advantages of fuzzy logic are: 1) It allows to formalize and simulate the report of an expert in the conduction and normalization of a process. 2) It provides a simple answer to the difficult modeling procedures. 3) It takes into consideration several variables and its weighted merger determines the magnitude of influence. 4) It continuously considers cases or exceptions of a different nature, integrating them into the solution. 5) They allow the imple- 
mentation of multicriteria strategies incorporating the knowledge of the experts.

The objective of this contribution is to show the implementation of fuzzy logic in business, management and accounting, through the research published in Scopus. This document has among its results the following sections: 1) Theory of fuzzy sets, in Business, Management and Accounting. 2) Analysis of the bibliometric of Fuzzy Logic in Business, Management and Accounting. 3) Identification and characterization of the most cited documents or seminal papers in fuzzy logic application in business, management and accounting.

\section{Material and Method}

The material used in this contribution is the documentation and bibliometric analysis tools contained in the Scopus academic research directory and the use of the VOSviewer software; the method, a bibliographic review and critical analysis of the results of the detected contributions.

Using the phrase "Fuzzy Logic" in the title of the contributions contained in the Scopus directory; and limiting these results to the subject area "Business, Management and Accounting", 397 documents were detected between 1983 and 2019. Using the bibliometric analysis tools that Scopus provides to its subscribers, Figure 2, Figure 4 and Figure 5 were achieved; In addition, the cited index of each of the investigations referred to in Table 1 and Table 2 was determined.

The bibliometric information of the 397 documents mentioned above was exported from the Scopus directory in two different formats. First, it was exported in (.ris) format, to be processed by the EndNote bibliometric management software. Through this computational tool all the citations contained in this work were generated. This bibliographic management tool allows to make citations by the norm selected by the user, for this work the bibliographic citation norm used was the American Psychological Association (APA). The use of this tool guarantees that each citation has in its reference the organization concerning the standard used and that, based on the integrity of the exported data, the reference has the greatest number of gifted fields.

Then the bibliometric information of the 397 documents was exported from the mentioned academic directory, but this time in (.csv) format. This process allowed us to use this information in the VOSviewer science bibliometric analysis software. The use of this software is justified by its potential in the process of visualization of productivity and orientation of scientific activity. By means of this tool, the density map of terms was obtained, made of text mining on the keywords of the articles detected.

\section{Results}

\subsection{Theory of Fuzzy Sets, in Business, Management and Accounting}

In classical theory an element belongs or does not belong to a set. This strict and determinant notion does not allow taking into account other frequently encoun- 
tered situations where an object may have certain belonging to a certain set (Karimi, Niknamfar, \& Niaki, 2019). For example; in a set of fruits clearly all are fruits, however, define which belong to the set of ripe fruits is more delicate since maturation is a gradual process. A diffuse set contains objects that do not have a precise delimitation to include elements with a certain degree of belonging to that set (Dostál \& Kruljacová, 2019; Geramian, Abraham, \& Ahmadi Nozari, 2019; Nadiri, Shokri, Tsai, \& Asghari Moghaddam, 2018).

The notion of fuzzy set is based on the concept of partial belonging where each element belongs partially or gradually to a set. A classic and simple example; suppose that a man is considered tall when his height is greater than $1.80 \mathrm{~m}$ and small when he is less than $1.40 \mathrm{~m}$. Where to include a man whose height is $1.78 \mathrm{~m}$ ? Obviously, that man intuitively has a higher degree of belonging to the group of tall men than to the group of small men. If it is treated classically, the degree of belonging to the group of tall men is zero or zero because it does not reach height and therefore should be considered a short man with full membership in that group.

In general, a diffuse set $Q$ of a universe $H$ is defined as:

$$
Q=\left\{\left(y, \mu_{Q(x)}\right) / y \in H ; \mu_{Q}(y) \in[0,1]\right\}
$$

which indicates that $Q$ is a set of pairs $\left(y, \mu_{Q(y)}\right)$,, where each $(y)$ belongs to the universe with a degree of belonging $\mu_{Q(y)}$ with values between zero and one. In classical theory we have:

$$
\mu_{Q(y)}=\left\{\begin{array}{l}
0 y \notin Q \\
1 y \in Q
\end{array}\right\}
$$

Example of the fuzzy set $Q$ of the numbers close to 1 . For this case it is assumed that the degree of belonging to the set is given by: $\mu_{Q(y)}=\mathrm{e}^{-2 *(n-1)^{2}}$.

Figure 1 shows the gradual behavior of belonging.

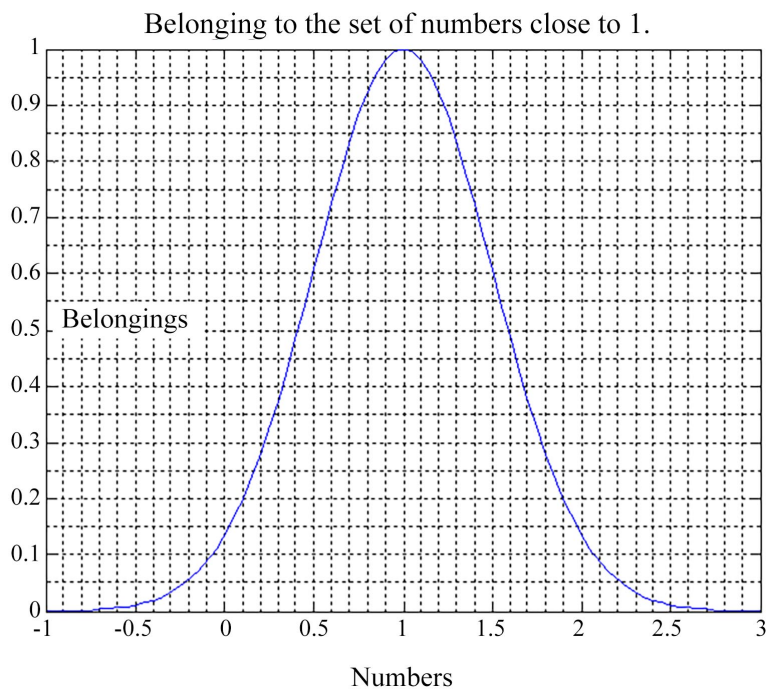

Figure 1. Belonging to the set of numbers close to 1 . 


\subsection{Analysis of the Bibliometric of Fuzzy LOGIC in Business, Management and Accounting}

Research in the application of fuzzy logic in business, management and accounting began at the beginning of the 80s. But they will be important in the scientific community at the beginning of the 21 st century. This is mainly due to the increase in market dynamics and business management (Brace, Gatarek, \& Musiela, 1997; Hsieh, 1991; Onnela, Chakraborti, Kaski, Kertész, \& Kanto, 2003). Figure 2 shows a clear trend in the increase of the application of this mathematical tool in research in management and accounting. This graphic shows the importance of the application of fuzzy logic in the solution of problems in the economic and business sciences.

Through analysis with the VOSviewer software, of the keywords of all the documents detected, the term density graph shown in Figure 3 was created. The areas with the highest density of terms are shown in red and the areas of lower density of terms in blue. The colors between red and blue are transitional zones. In this figure it can be observed that the term prevails in these scientific contributions in the area of economic and business sciences that use the mathematical criteria of the fuzzy logic is: decision making.

Both the emerging economic powers, such as India, and the established economic powers such as the United States of North America; they see in the application of the fuzzy logic in business, management and accounting, a practical and effective method in the solution of problems. Figure 4 shows the documents by country published.

In the last 29 years, the International Journal of Systems Assurance Engineering and Management has been the source of the greatest number of publications published on the topic: application of fuzzy logic in business, management and accounting. Segmented by journals: Knowledge Based Systems, Journal of Cleaner Production, Journal of Construction Engineering and Management and



Figure 2. Evolution of research in applications of fuzzy logic in the area of economic and business sciences (1983-2018) in Scopus. 
International Journal of Production Research, respectively. Figure 5 shows the aforementioned.

\subsection{Identification and Characterization of the Most Cited Documents or Seminal Papers in Application of Fuzzy LOGIC in Business, Management and Accounting}

To date there are only 10 revision-type papers in Scopus. The last review paper related to this topic was published in 2016. Table 1 identifies each of these documents.

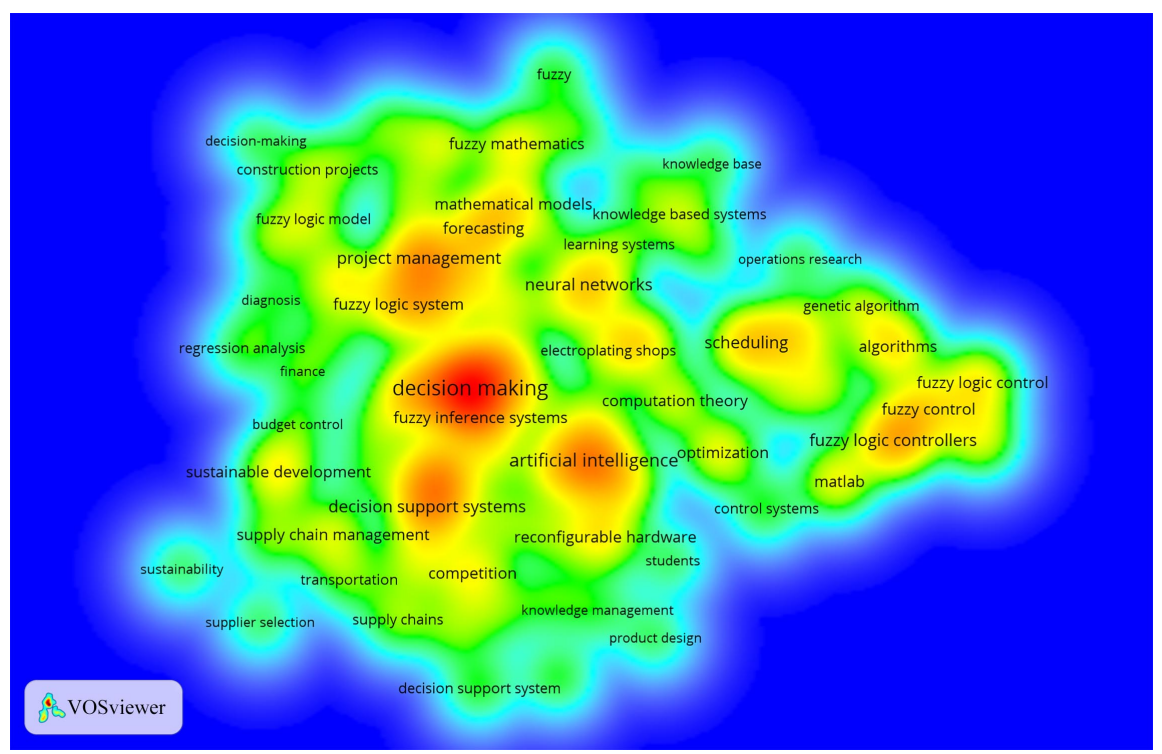

Figure 3. Term density map of the key words in the investigations detected in Scopus, under the aforementioned search criteria.

Documents by country or territory

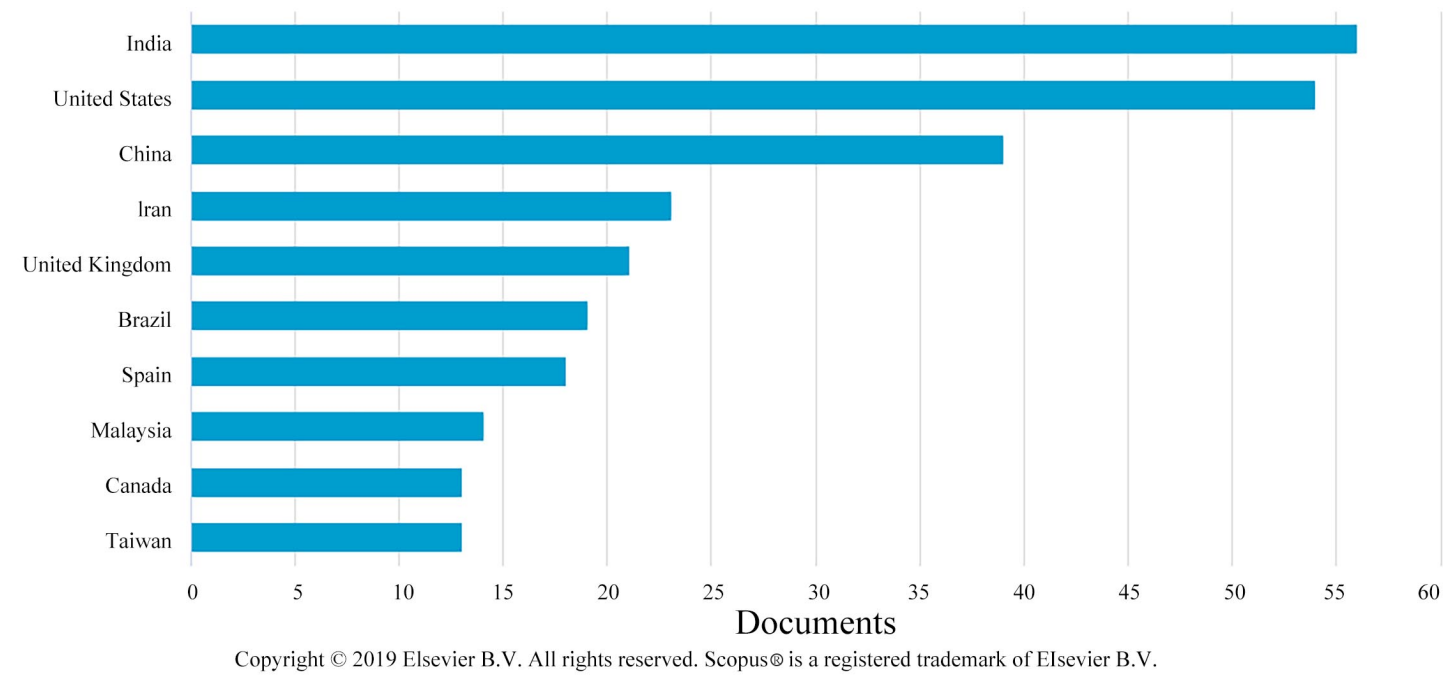

Figure 4. Documents by countries published in the academic directory Scopus. 


\section{Documents per year by source}

Compare the document counts for up to 10 sources.Compare sources and view CiteScore, SJR, and SNIP data

8

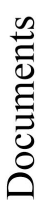

4

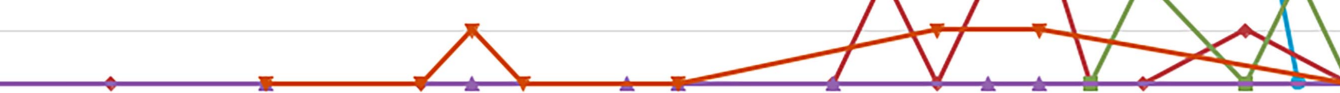

0

ప ڤ̆ Year

\footnotetext{
- International Journal Of Systems Assurance Engineering And Management $\quad$ ح Knowledge Based Systems

들-Journal Of Cleaner Production Journal Of Construction Engineering And Management

- International Journal Of Production Research

Copyright $\left(C 2019\right.$ Elsevier B.V. All rights reserved. Scopus ${ }^{\circledR}$ is a registered trademark of EIsevier B.V.
}

Figure 5. Documents per year by source, detected using the Scopus bibliometric tools.

Table 1. Documents type revision, detected.

\begin{tabular}{|c|c|c|c|c|}
\hline Title & Author & Date (oldest) & Cited by & Reference \\
\hline Fuzzy logic for evaluating alternative construction technology & $\begin{array}{l}\text { Chao, L. C. } \\
\text { Skibniewski, M. J. }\end{array}$ & 1998 & 22 & $\begin{array}{l}\text { (Chao \& } \\
\text { Skibniewski, 1998) }\end{array}$ \\
\hline $\begin{array}{l}\text { Clear logic and fuzzy guidance: A policy capturing study of merit } \\
\text { raise decisions }\end{array}$ & $\begin{array}{l}\text { Barclay, L. A. } \\
\text { York, K. M. }\end{array}$ & 2003 & 4 & $\begin{array}{l}\text { (Barclay \& York, } \\
\text { 2003) }\end{array}$ \\
\hline $\begin{array}{l}\text { Fuzzy logic and intelligent agents: Towards the next step of } \\
\text { capital budgeting decision support }\end{array}$ & $\begin{array}{l}\text { Collan, M. } \\
\text { Liu, S. }\end{array}$ & 2003 & 11 & (Collan \& Liu, 2003) \\
\hline $\begin{array}{l}\text { Fuzzy logic approach to prioritise engineering characteristics in } \\
\text { quality function deployment (FL-QFD) }\end{array}$ & $\begin{array}{l}\text { Ramasamy, N. R. } \\
\text { Selladurai, V. }\end{array}$ & 2004 & 42 & $\begin{array}{l}\text { (Ramasamy \& } \\
\text { Selladurai, 2004) }\end{array}$ \\
\hline Can fuzzy logic make technical analysis $20 / 20 ?$ & $\begin{array}{l}\text { Zhou, X. S. } \\
\text { Dong, M. }\end{array}$ & 2004 & 25 & $\begin{array}{l}\text { (Zhou \& Dong, } \\
\text { 2004) }\end{array}$ \\
\hline Linguistic fuzzy-logic game theory & Arfi, B. & 2006 & 15 & (Arfi, 2006) \\
\hline Paradigm shift - An introduction to fuzzy logic & Bih, J. & 2006 & 29 & $(\mathrm{Bih}, 2006)$ \\
\hline $\begin{array}{l}\text { Analysis of supplier related issues with implementation of fuzzy } \\
\text { logic for Indian textile organizations }\end{array}$ & $\begin{array}{l}\text { Kumar, D. } \\
\text { Singh, J. } \\
\text { Singh, O. P. }\end{array}$ & 2011 & 7 & $\begin{array}{l}\text { (Kumar, Singh, \& } \\
\text { Singh, 2011) }\end{array}$ \\
\hline $\begin{array}{l}\text { A literature review investigation on quality control charts based } \\
\text { on fuzzy logic }\end{array}$ & $\begin{array}{l}\text { Nasiri, M. } \\
\text { Darestani, S. A. }\end{array}$ & 2006 & 5 & $\begin{array}{l}\text { (Nasiri \& Darestani, } \\
\text { 2016) }\end{array}$ \\
\hline
\end{tabular}

The researchers Chao and Skibniewski (1998) presents an approach for the evaluation of new building construction technologies based on fuzzy logic algorithms, to make efficient and timely technology implementation decisions. The 
experimental results show that the approach can produce an increase of the available options, according to a set of linguistic rules defined by the user that establish the priorities in a specific project scenario. Their notions and methods are described in detail, illustrated by an example in which alternative methods are evaluated for the shuttering operation of a high-rise construction project.

In the paper of the authors Barclay and York (2003) Policy capturing was used to determine cue weights when a merit raise committee implemented an imprecise directive. The committee was consistent in their evaluations, but the policy was similar to that obtained by counting activities in faculty annual reports. Evaluations by three raters of 36 faculty were regressed on actual raises. This study has implications for organizations that motivate employees through merit pay decisions in ways that are inconsistent with their mission and business objectives.

Collan and Liu (2003) they expressed that: To proceed in an efficient and precise way in the dynamic management of large investments, managers must have constant access to information on the real-time situation of the investment, as well as access to up-to-date information on changes in the business environment. In other words, the economic existence of large investment processes requires a permanent dynamic management, currently. This contribution studies how emerging software technologies will help provide better support in this scenario. In addition, they will provide a support system that will make an integrated application of the technologies. Integrates traditional and modern methods for capital budgeting and investment decision making, then presents a vision of the investment management process based on the real option framework, and develops a holistic framework for a capital budget system facilitated by agents that uses a real option approach based on fuzzy logic. On the other hand, it studies how smart agents can be applied to compile information on decisions and to facilitate the integration of prospective information in the capital budgeting process, and how agents can be built. As a final result of this investigation, the administrative implications of the technology supporting the proposed decision are explained.

Ramasamy and Selladurai (2004) they explained that: Quality function deployment (QFD) is a proven tool for process and product development, which translates the voice of customer ( $\mathrm{VoC}$ ) into engineering characteristics (EC), and prioritizes the ECs, based on the customer's requirements. Conventional QFD evaluates these targets for crisp weights of the customer attributes (CA), identified from the VoCs. The VoCs are not crisp and generally exhibit a well-defined distribution. Crisp weights assigned to non-crisp CAs can lead to wrong prioritization of the EC. In the past, fuzzy numbers have been used to represent the imprecise nature of these judgements and to define more appropriately the relationship between EC and CA. This paper proposes fuzzy logic-quality function deployment (FL-QFD) - the use of fuzzy logic principles in QFD. It is an innovative method of determining optimum rating of ECs by simulating the QFD ma- 
trix for randomized CA rating in the fuzzed range. The rule-based knowledge system defines the relationship between the ECs and the CAs. The flexible manufacturing system (FMS) design problem investigated by Khoo and Hot (1996) is presented to show the application of the proposed model. The results are compared and examined to study the effect of the CA on prioritizing the EC. The paper addresses the issue of defining non-crisp customer attributes in the QFD, and offers practical help to an individual intending to further investigate the proposed model.

Zhou and Dong (2004) in their work they indicated: In the technical analysis the automatic detection of technical patterns that would be detected in a similar way by the eyes of the experts, represents a great challenge for the scientific community focused on this type of problem. The results of this research represent a powerful tool for investors, because it allows them to incorporate human cognition (experience) into historical trade statistics to form future winning strategies. In this study, cognitive uncertainty was incorporated into the technical analysis by using an approach based on fuzzy logic. The results show that the algorithm can detect subtle differences in a clearly defined pattern.

Kent (2005) in his investigation he explained: When studies are combined combining factors, traditional analyzes focused on the variables of marketing data are not suitable for the discovery of logical relationships. This contribution sustains that it is necessary to rethink what we understand by "case" and to see the cases as configurations of characteristics instead of units of analysis. The processes of use of combinatorial logic and fuzzy logic are explained. In addition, a novel piece of software is generated and applied to a set of data to compare the results of the traditional analysis and the qualitative comparative analysis of fuzzy sets.

Arfi (2006) in his search he explained: The novel contribution of this contribution is that it develops an approach to game theory, based not on the Boolean logic of two values, but on the fuzzy linguistic logic. Diffuse linguistic logic is defined by two key characteristics. First, the truth values of logical propositions encompass a set of linguistic terms as true, very true, almost false, very false and false. Second, this method allows logical categories to overlap in contrast to Boolean logic, where the two possible logical categories, "true" and "false", are clearly distinct. A game becomes a game of fuzzy linguistic logic by converting the strategies into diffuse linguistic strategies, the preferences of the players into diffuse linguistic preferences, and the reasoning rules and inferences of the game into the linguistic fuzzy reasoning that operate in accordance with the diffuse linguistic logic. This leads to the introduction of a new notion of linguistic blurry linguistic dominance and Nash equilibrium.

Bih (2006) in his study he explained: Fuzzy logic is aimed at approaching human decision making using natural language terms instead of quantitative terms. An important aspect of fuzzy logic includes the concept of linguistic variable whose values are words or sentences in natural language. The knowledge of 
fuzzy logic has created a paradigm shift in various areas of the theoretical and applied sciences. It facilitates the spoken interaction between the user and the machine, in both directions. The leadership of fuzzy logic algorithms in a digital and interconnected world is undeniable, automating decisions, intelligently analyzing a large amount of data and learning from errors. Fuzzy logic that has a huge potential will provide the best performance by integrating it with the management of big data, artificial intelligence, neural networks and end-user techniques.

Kumar et al. (2011), This research is based on the data obtained in a survey process of 66 textile clothing companies in India, with the purpose of optimizing the decision-making process regarding the selection of the best suppliers. Using the information obtained from the surveys, the theory of fuzzy sets was applied to arrive at a decision on the choice or rejection of a particular provider. Four multiple-input Mamdani single-output (MISO) fuzzy inference systems have been proposed. The first three MISO systems consist of three inputs, four inputs and three inputs, respectively, and provide a single output each. These three outputs are used as inputs for the fourth MISO system to give single output, which is called final decision.

The researchers Nasiri and Darestani (2016) in his paper he explained: In order to sustain and increase the quality and efficiency of products and services, the business sector demands quality control tools that are optimal, fast and efficient. Under this premise and considering that accurate data are not always available, fuzzy logic algorithms can conveniently model the processes in which the observed data are inaccurate. For these reasons, researchers have focused on fuzzy control charts that adapt to the uncertainty due to lack of clarity. Due to the importance of fuzzy control charts, this research reviewed the literature on fuzzy control charts from 1990 to 2012. Based on the objective of this document, the fuzzy application of control charts was analyzed. Regarding the year of publication, the title of the journal, the affiliation of the author, the data source, the classification of the diffuse theory, the classification of the control charts and the place of research. The results showed positive trends in increase in the investigations that occurred in the last decade. In summary, the results showed that the use of fuzzy set theory in the control chart is still necessary for further investigation of performance criteria, membership function, distribution, heuristic methods, and attribute control chart.

\section{Discussion}

Regularly, various methods are used for decision making in business, administration and accounting processes: classics and methods that use soft computing (Dostál et al., 2018; Nasibov, Demir, \& Vahaplar, 2019; Srivastava, Pant, \& Agrawal, 2018). The decision-making processes are very complex and varied, because they include political, social, psychological, economic, financial phenomena and so on. Many variables are difficult to measure and control; they are 
characterized by imprecision, uncertainty, vagueness, approximation and non-linearity. Fuzzy logic differs from conventional computing in that it tolerates inaccuracy, uncertainty and approximation (Sivamani et al., 2017). In effect, the model to follow for fuzzy logic is the human mind (Somasundaram \& Genish, 2014). The guiding principle of fuzzy logic is to exploit this tolerance to achieve management capacity, robustness and low cost of solution. Table 2 contains the most cited investigations, detected within the Scopus academic directory and related to the application of fuzzy logic in business, management and accounting. These investigations reflect the potentialities of fuzzy logic in these lines of research and their future projections.

Flexible computing symbolizes a paradigm shift in computing design, a change that reflects the fact that the human mind, unlike today's computers, possesses an important capacity to store and process information that is inaccurate and approximate (Sheeba \& Vivekanandan, 2016; Yager \& Zadeh, 2012).

Fuzzy logic in business, management and accounting applications have specific characteristics. They can help in the decentralization of decision-making processes so that they are standardized, reproducible and documented. These methods play very important roles in companies because they help reduce costs, and that can generate higher profits; they can also help companies compete successfully and decrease expenses.

Table 2. These are the most cited articles according to Scopus's bibliometric.

\begin{tabular}{|c|c|c|c|c|c|c|c|}
\hline & Title & Author & Year & Cite by & Source title & Abstract & Reference \\
\hline 1 & $\begin{array}{l}\text { A proposal for } \\
\text { construction } \\
\text { project risk } \\
\text { assessment using } \\
\text { fuzzy logic }\end{array}$ & $\begin{array}{l}\text { Tah, } \\
\text { J. H. M. } \\
\text { Carr, V. }\end{array}$ & 2000 & 204 & $\begin{array}{l}\text { Construction } \\
\text { Management } \\
\text { and } \\
\text { Economics }\end{array}$ & $\begin{array}{l}\text { The construction industry is plagued by risk and often } \\
\text { has suffered poor performance as a result. There are a } \\
\text { number of risk management techniques available to } \\
\text { help alleviate this, but usually these are based on } \\
\text { operational research techniques developed in the } \\
\text { 1960s, and for the most part have failed to meet the } \\
\text { needs of project managers. In this paper, a hierarchical } \\
\text { risk breakdown structure representation is used to } \\
\text { develop a formal model for qualitative risk assessment. } \\
\text { A common language for describing risks is presented } \\
\text { which includes terms for quantifying likelihoods and } \\
\text { impacts so as to achieve consistent quantification. The } \\
\text { relationships between risk factors, risks and their } \\
\text { consequences are represented on cause and effect } \\
\text { diagrams. These diagrams and the concepts of fuzzy } \\
\text { association and fuzzy composition are applied to } \\
\text { identify relationships between risk sources and the } \\
\text { consequences for project performance measures. A } \\
\text { methodology for evaluating the risk exposure, } \\
\text { considering the consequences in terms of time, cost, } \\
\text { quality, and safety performance measures of a project } \\
\text { based on fuzzy estimates of the risk components is } \\
\text { presented. }\end{array}$ & $\begin{array}{l}\text { (Tah \& Carr, } \\
2000)\end{array}$ \\
\hline
\end{tabular}


Agility Lin, C. T.

2 evaluation using fuzzy logic
Chiu, $\mathrm{H}$.

2006

Tseng, Y. H.
A

fuzzy-logic-based

decision-making Büyüközkan, G. approach for new Feyziog̃lu, $\mathrm{O}$.

product

development
"Change" seems to be one of enterprises' major characteristics in this new competitive era. Agile enterprise whereby an organization can change and adapt quickly to changing circumstances is increasingly viewed as a winning strategy. However, in embracing agile enterprise, there are important questions to be asked: what precisely is agility and how can it be measured? How can one assist in achieving and enhancing agility effectively? Answers to such questions are critical to the practitioners and to the theory of agile enterprise design. The foundation of agile enterprise lies in the integration of information International system/technologies, people, business processes and Journal of facilities. Due to the ill-defined and vague indicators Production which exist within agility assessment, most measures are described subjectively by linguistic terms which are characterized by ambiguity and multi-possibility, and the conventional assessment approaches cannot suitably nor effectively handle such measurement. However, fuzzy logic provides a useful tool for dealing with decisions in which the phenomena are imprecise and vague. Thus, the novelty in the paper is development of the absolute agility index, a unique and unprecedented attempt in agility measurement, using fuzzy logic to address the ambiguity in agility evaluation. Details of the approach and a framework of a fuzzy agility evaluation will be presented. An example is also used to illustrate the approach developed.

The managers spend most of their time to take critical decisions in each level of the organizational hierarchy. Basically, the decision process is to weight diverse alternatives each having the purpose to attain some of the desired objectives and to figure out the best solution in the complete challenging goals set. In today's rapidly changing and highly uncertain environment, the strategic decisions have an extremely complex and fuzzy nature. In the meantime, the enterprises have tendency to appreciate the new International product development (NPD) activities so as to deal
Journal of

Production

Economics with the innovation in the new economy and to fulfill the customer demands adequately. The aim of this study is then to improve the accuracy of decision-making in NPD under uncertainty. We first identify the decision points in the NPD process and the uncertainty factors affecting those points. Next, we determine the necessary decision models and techniques to help the decision makers to reduce their risks. Finally, we propose an integrated approach based on fuzzy logic to shape the decisions and illustrate with an application in software development. ๑ 2003 Elsevier Science B.V. All rights reserved. 


\section{Continued}

Ecological complexity, fuzzy

4 logic, and holism in indigenous

knowledge
Berkes, F. $\begin{array}{llll}\text { Berkes, F. } & 2009 & 102 & \text { Futures }\end{array}$
Development of a

logic

Some indigenous knowledge is said to be holistic in the way it deals with the environment. Given the difficulties of Western science with complex environmental problems, any insights from the holism of indigenous knowledge are of major interest. Based on examples from Inuit and other northern peoples, it appears that indigenous knowledge approaches complex systems by using simple prescriptions consistent with fuzzy logic. Specifically, indigenous knowledge pursues holism through the continued reading of the environment, collection of large amounts of information, and the construction of collective mental models that can adjust to new information. Such an approach serves the assessment of a large number of variables qualitatively, as opposed to focusing on a small number of variables quantitatively.

Purpose: This paper aims to provide a tool for decision makers to help them with selection of the appropriate supplier. Design/methodology/approach: Companies often depend on their suppliers to meet customers' demands. Thus, the key to the success of these companies is selection of the appropriate supplier. A methodology is proposed to address this issue by first identifying the appropriate selection criteria and then developing a mechanism for their inclusion and measurement in the evaluation process. Such an evaluation process requires decision maker's preferences on the importance of these criteria as inputs. Findings: Human assessments contain some degree of subjectivity that often cannot be expressed in pure numeric scales and requires linguistic expressions. To capture this subjectivity the authors have applied fuzzy logic that allows the decision makers to express
Supply Chain Management their preferences/opinions in linguistic terms. Decision maker's preferences on appropriate criteria as well as his/her perception of the supplier performance with respect to these criteria are elicited. Fuzzy membership functions are used to convert these preferences expressed in linguistic terms into fuzzy numbers. Fuzzy mathematical operators are then applied to determine a fuzzy score for each supplier. These fuzzy scores are in turn translated into crisp scores to allow the ranking of the suppliers. The proposed methodology is multidisciplinary across several diverse disciplines like mathematics, psychology, and operations management. Practical implications: The procedure proposed here can help companies to identify the best supplier. Originality/value: The paper describes a decision model that incorporates decision maker's subjective assessments and applies fuzzy arithmetic operators to manipulate and quantify these assessments. 
Evaluating the

information

$$
\text { sharing }
$$

6 capabilities of supply chain partners: A fuzzy logic model
Shore, B.

Venkatachalam, $2003 \quad 84$

A. R.
Physical

Distribution

and Logistics

Management
Competitive advantage is often determined by the effectiveness of an organization's supply chain, and as a result, the evaluation and selection of suppliers has become an increasingly important management activity. But the evaluation process is complex. The data that must be considered are both technical and social/organizational. Much of the data are difficult to obtain and ambiguous or vague to interpret. In addition, the dynamic global environment of changing exchange rates, economic conditions, and technical

International infrastructure, demand that the pool of potential suppliers be re-evaluated periodically. Nonetheless, a rational process of evaluation must exist to select the most appropriate suppliers. This paper addresses one dimension of the evaluation process, the information sharing capability of potential supply chain partners. It is an especially important dimension since information technology is necessary to horizontally integrate geographically dispersed operations. Fuzzy logic, a subset of artificial intelligence, together with analytical hierarchy process is used to model this process and rank potential suppliers. It is an appropriate methodology to use for this application and has the potential to be used with other supply chain design decisions since it explicitly handles vague, ambiguous, and imprecise data.

Manufacturing decisions inherently face uncertainties and imprecision. Fuzzy logic, and tools based on fuzzy logic, allow for the inclusion of uncertainties and imperfect information in decision making models, making them well suited for manufacturing decisions. (Azadegan, In this study, we first review the progression in the use Porobic,

International Journal of Production Economics Ghazinoory, S. manufacturing: specialized application

Kheirkhah, A.
$2011 \quad 80$ of fuzzy tools in tackling different manufacturing issues Ghazinoory, during the past two decades. We then apply fuzzy linear Samouei, \& programming to a less emphasized, but important issue Saman in manufacturing, namely that of product mix Kheirkhah, prioritization. The proposed algorithm, based on linear 2011) programming with fuzzy constraints and integer variables, provides several advantages to existing algorithm as it carries increased ease in understanding, in use, and provides flexibility in its application.

We present an interactive user-friendly microcomputer-based decision support system for consensus reaching processes. The point of departure is a group of individuals (experts, decision makers ...) who present their testimonies (opinions) in the form of individual fuzzy preference relations. Initially, these opinions are usually quite different, i.e., the group is far from consensus. Then, in a multistage session a moderator, who is supervising the session, tries to make Kacprzyk, \& the individuals change their testimonies by, e.g., rational Zadrozny, 1988) argument, bargaining, etc. to eventually get closer to consensus. For gauging and monitoring the process a new "soft" degree (measure) of consensus is used whose essence is the determination to what degree, e.g., "most of the individuals agree as to almost all of the relevant options". A fuzzy-logic-based calculus of linguistically quantified propositions is employed. 


\section{Continued}

9

zzy-logic-based Machacha, L. L. approach to Bhattacharya, $\mathrm{P}$. project selection
When making decisions we need to consider the possible alternatives and then choose the optimal alternative. The uncertainty of subjective judgment is present during this selection process. Also, decision making becomes difficult when the available information is incomplete or imprecise. This kind of problem exists while selecting a project. There are also several critical factors that are involved in the selection process, including market conditions, availability of IEEE raw materials, etc. The decision mechanism is Transactions constrained by the uncertainty inherent in the on determination of the relative importance of each Engineering attribute element. In this paper, we develop a system Management for the project selection using fuzzy logic. Fuzzy logic reduction. The quantification of leanness is one of the

Fuzzy logic-based leanness

10 assessment and its decision Vinodh, S. Balaji, S. R. 2011 70 support system
International organization. During this research study, a leanness Journal of measurement model has been designed. Then the Production Research computation is time consuming and error-prone, a enables us to emulate the human reasoning process and make decisions based on vague or imprecise data. Our approach is based on uncertainty reduction. The optimal alternative is formed by the relative weights of each attribute's elements combined over all the attribute membership functions. We also do a case study for the selection of software packages. Our system could be easily applied to other project selection problems under uncertainty.

Manufacturing organizations have been witnessing a transition from mass manufacturing to lean manufacturing. Lean manufacturing is focused on the elimination of obvious wastes occurring in the manufacturing process, thereby enabling cost contemporary research agendas of lean manufacturing. This paper reports a study which is carried out to assess the leanness level of a manufacturing

(Machacha \& Bhattacharya, 2000) leanness index has been computed. Since the manual Balaji, 2011) computerized decision support system has been developed. This decision support system has been designated as FLBLA-DSS (decision support system for fuzzy logic-based leanness assessment). FLBLA-DSS computes the fuzzy leanness index, Euclidean distance and identifies the weaker areas which need improvement. The developed DSS has been test implemented in an Indian modular switch manufacturing organization.

Fuzzy logic models are not a black box; because the rules are defined. The advantages of fuzzy logic can be found in the configuration of rules of phenomena and processes of great complexity and their ability to adjust and simulate before implementation. Neuro-fuzzy models could be an advantage in the configuration of rules (Lin \& Lee, 1991; Zadeh, 1994).

In the future it is expected that this computational practice will focus fundamentally on new diffuse models and the combination of these with other artifi- 
cial intelligence techniques such as neural networks, genetic algorism, forage bacteria, among others. Future scientific contributions will focus on various applications to allow business decision making to be faster and more precise, this will be the main research focus because the amount of data to be processed increases exponentially in business, management and accounting. More and more decisions will be made by automatic systems without the timely influence of the analyst (Nasiri \& Darestani, 2016; Singhal, Ranganth, Batra, \& Nanda, 2016).

The evolution of rapid, more precise, partially or fully automated decision-making systems is where flexible computing methods will be used. They will save time, reduce errors, prevent human failures and reduce costs, thus, favoring the competitiveness of companies (Dostál \& Kruljacová, 2019; Geramian et al., 2019; Plessis et al., 2018).

The contributions of fuzzy logic in business, management and accounting have advantageous consequences: in many cases, a problem can be solved effectively and agile using this mathematical method (Dostál et al., 2018; Zohuri \& Moghaddam, 2017). The rapid growth in the number and variety of applications of fuzzy logic methods, together with the growing interest of the international scientific community, demonstrates the value of this practice, and suggest that its impact will increasingly be felt in the coming years in the world of business, management and accounting.

\section{Limitations of the Study}

- This research is limited to the analysis of documents published in the academic directory Scopus.

- Only paper written in English is studied.

- Only analyze the scientific publications between the years 1983 and 2019.

- The number of citations per investigation, shown in Table 1 only refers to citations made by research published in Scopus.

- The analysis of text mining to make the map of terms of Figure 3 is only done in the keywords of the articles detected.

\section{Conclusion}

Fuzzy logic is a theory that uses fuzzy sets and very precise rules. This mathematical method uses linguistic variables, the base of rules or fuzzy sets are easily modified, the input and output are related in linguistic terms, they are easily understood and some rules cover a great complexity. The applications of fuzzy logic for the solution of problems in the field of denial, administration and accounting activity have had a notable increase in the international scientific community, in recent decades. This condition will continue in the future given the dynamism and the large amount of information that is currently handled in the areas of economic and business sciences. On the other hand, the application of fuzzy logic in this field finds its greatest utility, in models or algorithms for decision making. In the future, it is expected that this computational practice 
will focus fundamentally on new diffuse models and the combination of these with other artificial intelligence techniques such as neural networks, genetic algorism, forage bacteria, among others. Future scientific contributions will focus on various applications to allow business decision making to be faster and more precise. This will be the main research focus, because the amount of data to be processed increases exponentially in the subject area: business, management and accounting.

\section{Conflicts of Interest}

The authors declare no conflicts of interest regarding the publication of this paper.

\section{References}

Al Nahyan, M. T., Hawas, Y. E., Aljassmi, H., \& Maraqa, M. (2018). Capturing the Stakeholders' Managerial Competency Risks of Mega Infrastructure Projects: A Fuzzy Logic Modelling Approach. International Journal of Project Organisation and Management, 10, 109-136. https://doi.org/10.1504/IJPOM.2018.092087

Almutairi, A. M., Salonitis, K., \& Al-Ashaab, A. (2019). Assessing the Leanness of a Supply Chain Using Multi-Grade Fuzzy Logic: A Health-Care Case Study. International Journal of Lean Six Sigma, 10, 81-105. https://doi.org/10.1108/IJLSS-03-2018-0027

Arfi, B. (2006). Linguistic Fuzzy-Logic Game Theory. Journal of Conflict Resolution, 50, 28-57. https://doi.org/10.1177/0022002705284708

Azadegan, A., Porobic, L., Ghazinoory, S., Samouei, P., \& Saman Kheirkhah, A. (2011). Fuzzy Logic in Manufacturing: A Review of Literature and a Specialized Application. International Journal of Production Economics, 132, 258-270. https://doi.org/10.1016/j.ijpe.2011.04.018

Barclay, L. A., \& York, K. M. (2003). Clear Logic and Fuzzy Guidance: A Policy Capturing Study of Merit Raise Decisions. Public Personnel Management, 32, 287-299. https://doi.org/10.1177/009102600303200208

Berkes, F., \& Berkes, M. K. (2009). Ecological Complexity, Fuzzy Logic, and Holism in Indigenous Knowledge. Futures, 41, 6-12. https://doi.org/10.1016/j.futures.2008.07.003

Bih, J. (2006). Paradigm Shift-An Introduction to Fuzzy Logic. IEEE Potentials, 25, 6-21. https://doi.org/10.1109/MP.2006.1635021

Bolloju, N. (1996). Formulation of Qualitative Models Using Fuzzy Logic. Decision Support Systems, 17, 275-298. https://doi.org/10.1016/0167-9236(96)00005-X

Brace, A., Gatarek, D., \& Musiela, M. (1997). The Market Model of Interest Rate Dynamics. Mathematical Finance, 7, 127-155. https://doi.org/10.1111/1467-9965.00028

Bravo Hidalgo, D. (2015). Climatización solar de edificaciones. Centro Azúcar, 42, 72-82.

Bravo Hidalgo, D., \& León González, J. L. (2018). Divulgación de la investigación científica en el Siglo XXI. Revista Universidad y Sociedad, 10, 88-97.

Büyüközkan, G., \& Feyziog̃lu, O. (2004). A Fuzzy-Logic-Based Decision-Making Approach for New Product Development. International Journal of Production Economics, 90, 27-45. https://doi.org/10.1016/S0925-5273(02)00330-4

Chakraborty, J. N., Ravi, Shivangi, Vanshika, \& Vishal (2019). Recipe Prediction in Textile Coloration Using Artificial Neural Network and Fuzzy Logic. Asian Textile Journal, $28,62-66$ 
Chao, L. C., \& Liaw, S. J. (2019). Fuzzy Logic Model for Determining Minimum Overheads-Cum-Markup Rate. Journal of Construction Engineering and Management, 145, Article ID: 04019008. https://doi.org/10.1061/(ASCE)CO.1943-7862.0001632

Chao, L. C., \& Skibniewski, M. J. (1998). Fuzzy Logic for Evaluating Alternative Construction Technology. Journal of Construction Engineering and Management, 124, 297-304. https://doi.org/10.1061/(ASCE)0733-9364(1998)124:4(297)

Collan, M., \& Liu, S. (2003). Fuzzy Logic and Intelligent Agents: Towards the Next Step of Capital Budgeting Decision Support. Industrial Management and Data Systems, 103, 410-422. https://doi.org/10.1108/02635570310479981

Díaz Córdova, J. F., Coba Molina, E., \& Navarrete, P. (2017). Fuzzy Logic and Financial Risk. A Proposed Classification of Financial Risk to the Cooperative Sector. Contaduría y Administración, 62, 1670-1686. https://doi.org/10.1016/j.cya.2017.09.001

Djekic, I., Smigic, N., Glavan, R., Miocinovic, J., \& Tomasevic, I. (2018). Transportation Sustainability Index in Dairy Industry-Fuzzy Logic Approach. Journal of Cleaner Production, 180, 107-115. https://doi.org/10.1016/j.jclepro.2018.01.185

Dostál, P., \& Kruljacová, A. (2019). Evaluation of University Quality via Fuzzy Logic.

Dostál, P., \& Lin, C. Y. (2018). Business Applications of Fuzzy Logic. In The Oxford Handbook of Computational Economics and Finance (pp. 360-396). Oxford: Oxford University Press. https://doi.org/10.1093/oxfordhb/9780199844371.013.14

Dostál, P., Rukovanský, I., \& Králik, J. (2018). Economic Risk Evaluation via Fuzzy Logic.

Fedrizzi, M., Kacprzyk, J., \& Zadrozny, S. A. (1988). An Interactive Multi-User Decision Support System for Consensus Reaching Processes Using Fuzzy Logic with Linguistic Quantifiers. Decision Support Systems, 4, 313-327. https://doi.org/10.1016/0167-9236(88)90019-X

Geramian, A., Abraham, A., \& Ahmadi Nozari, M. (2019). Fuzzy Logic-Based FMEA Robust Design: A Quantitative Approach for Robustness against Groupthink in Group/Team Decision-Making. International Journal of Production Research, 57, 1331-1344. https://doi.org/10.1080/00207543.2018.1471236

Grekousis, G., Manetos, P., \& Photis, Y. N. (2013). Modeling Urban Evolution Using Neural Networks, Fuzzy Logic and GIS: The Case of the Athens Metropolitan Area. Cities, 30, 193-203. https://doi.org/10.1016/j.cities.2012.03.006

Halabi, D., \& Shaout, A. (2019). Website Tenders Evaluation Using Fuzzy Logic. International Journal of Information Systems in the Service Sector, 11, 32-50. https://doi.org/10.4018/IJISSS.2019040103

Hidalgo, D. B., \& Guerra, Y. P. (2016). Eficiencia energética en la climatización de edificaciones. Revista Publicando, 3, 218-238.

Hsieh, D. A. (1991). Chaos and Nonlinear Dynamics: Application to Financial Markets. The Journal of Finance, 46, 1839-1877. https://doi.org/10.1111/j.1540-6261.1991.tb04646.x

Karimi, M., Niknamfar, A. H., \& Niaki, S. T. A. (2019). An Application of Fuzzy-Logic and Grey-Relational ANP-Based SWOT in the Ceramic and Tile Industry. Knowledge-Based Systems, 163, 581-594. https://doi.org/10.1016/j.knosys.2018.09.020

Kent, R. A. (2005). Cases as Configurations: Using Combinatorial and Fuzzy Logic to Analyse Marketing Data. International Journal of Market Research, 47, 205-228. https://doi.org/10.1177/147078530504700202

Khoo, L. P., \& Hot, N. C. (1996). Framework of a Fuzzy Quality Function Deployment System. International Journal of Production Research, 34, 299-311. https://doi.org/10.1080/00207549608904904 
Knight, K., \& Fayek, A. R. (2002). Use of Fuzzy Logic for Predicting Design Cost Overruns on Building Projects. Journal of Construction Engineering and Management, 128, 503-512. https://doi.org/10.1061/(ASCE)0733-9364(2002)128:6(503)

Kokles, M., Filanová, J., \& Korček, F. (2016). Application of Fuzzy Logic in the Process of Information Security Risk Assessment.

Kumar, D., Singh, J., \& Singh, O. P. (2011). Analysis of Supplier Related Issues with Implementation of Fuzzy Logic for Indian Textile Organizations. International Journal of Logistics Systems and Management, 10, 313-339. https://doi.org/10.1504/IJLSM.2011.043120

Kunsch, P. L., \& Vander Straeten, M. (2015). The Cost of a Nuclear-Fuel Repository: A Criterion Valuation by Means of Fuzzy Logic. In Evaluation and Decision Models with Multiple Criteria: Case Studies (p. 311). Berlin: Springer.

https://doi.org/10.1007/978-3-662-46816-6_11

Kushwaha, N., \& Suryakant (2014). Software Cost Estimation Using the Improved Fuzzy Logic Framework. Conference on IT in Business, Industry and Government (CSIBIG), Indore, 8-9 March 2014, 211-224. https://doi.org/10.1109/CSIBIG.2014.7056959

Levy, J., Mallach, E., \& Duchessi, P. (1991). A Fuzzy Logic Evaluation System for Commercial Loan Analysis. Omega (United Kingdom), 19, 651-669. https://doi.org/10.1016/0305-0483(91)90014-K

Lin, C. T., Chiu, H., \& Tseng, Y. H. (2006). Agility Evaluation Using Fuzzy Logic. International Journal of Production Economics, 101, 353-368. https://doi.org/10.1016/j.ijpe.2005.01.011

Lin, C. T., \& Lee, G. C. S. (1991). Neural-Network-Based Fuzzy Logic Control and Decision System. IEEE Transactions on Computers, 40, 1320-1336. https://doi.org/10.1109/12.106218

Machacha, L. L., \& Bhattacharya, P. (2000). A Fuzzy-Logic-Based Approach to Project Selection. IEEE Transactions on Engineering Management, 47, 65-73. https://doi.org/10.1109/17.820726

Morano, P., Locurcio, M., Tajani, F., \& Guarini, M. R. (2015). Fuzzy Logic and Coherence Control in Multi-Criteria Evaluation of Urban Redevelopment Projects. International Journal of Business Intelligence and Data Mining, 10, 73-93. https://doi.org/10.1504/IJBIDM.2015.069041

Mujahid, S. N., \& Duffuaa, S. O. (2007). Process Targeting of Multi-Characteristic Product Using Fuzzy Logic and Genetic Algorithm with an Interval Based Taguchi Cost Function. 2007 IEEE International Conference on Industrial Engineering and Engineering Management, Singapore, 2-4 December 2007, 14-32.

https://doi.org/10.1109/IEEM.2007.4419383

Nadiri, A. A., Shokri, S., Tsai, F. T. C., \& Asghari Moghaddam, A. (2018). Prediction of Effluent Quality Parameters of a Wastewater Treatment Plant Using a Supervised Committee Fuzzy Logic Model. Journal of Cleaner Production, 180, 539-549. https://doi.org/10.1016/j.jclepro.2018.01.139

Nasibov, E., Demir, M., \& Vahaplar, A. (2019). A Fuzzy Logic Apparel Size Decision Methodology for Online Marketing. International Journal of Clothing Science and Technology, 31, 299-315. https://doi.org/10.1108/IJCST-06-2018-0077

Nasiri, M., \& Darestani, S. A. (2016). A Literature Review Investigation on Quality Control Charts Based on Fuzzy Logic. International Journal of Productivity and Quality Management, 18, 474-498. https://doi.org/10.1504/IJPQM.2016.077778

Onnela, J. P., Chakraborti, A., Kaski, K., Kertész, J., \& Kanto, A. (2003). Dynamics of 
Market Correlations: Taxonomy and Portfolio Analysis. Physical Review E-Statistical, Nonlinear, and Soft Matter Physics, 68, 561101-5611012. https://doi.org/10.1103/PhysRevE.68.056110

Ordoobadi, S. M. (2009). Development of a Supplier Selection Model Using Fuzzy Logic. Supply Chain Management, 14, 314-327. https://doi.org/10.1108/13598540910970144

Osiro, L., Lima-Junior, F. R., \& Carpinetti, L. C. R. (2014). A Fuzzy Logic Approach to Supplier Evaluation for Development. International Journal of Production Economics, 153, 95-112. https://doi.org/10.1016/j.ijpe.2014.02.009

Ouahli, J., \& Cherkaoui, A. (2019). Team Performance Assessment within Fuzzy Logic.

Pislaru, M., Alexa, L., \& Avasilcăi, S. (2018). Assessment of Project Management Implementation Based on Fuzzy Logic Approach.

Plessis, E. D., Martin, J. C., Roman, C., \& Slabbert, E. (2018). Fuzzy Logic to Assess Service Quality at Arts Festivals. Event Management, 22, 501-516. https://doi.org/10.3727/152599518X15264726192442

Ramasamy, N. R., \& Selladurai, V. (2004). Fuzzy Logic Approach to Prioritise Engineering Characteristics in Quality Function Deployment (FL-QFD). International Journal of Quality and Reliability Management, 21, 1012-1023. https://doi.org/10.1108/02656710410561826

Sharma, P., \& Saxena, K. (2017). Application of Fuzzy Logic and Genetic Algorithm in Heart Disease Risk Level Prediction. International Journal of Systems Assurance Engineering and Management, 8, 1109-1125. https://doi.org/10.1007/s13198-017-0578-8

Sheeba, J. I., \& Vivekanandan, K. (2016). Extracting Keywords from Budget Transcripts Using Fuzzy Logic. International Journal of Data Mining, Modelling and Management, 8, 62-74. https://doi.org/10.1504/IJDMMM.2016.075967

Shore, B., \& Venkatachalam, A. R. (2003). Evaluating the Information Sharing Capabilities of Supply Chain Partners: A Fuzzy Logic Model. International Journal of Physical Distribution and Logistics Management, 33, 804-824. https://doi.org/10.1108/09600030310503343

Singhal, S., Ranganth, M. S., Batra, R., \& Nanda, S. (2016). Application of Fuzzy Logic and Fuzzy Systems in Machining: A Literature Review.

Sivamani, S., Kim, H. G., Park, J., \& Cho, Y. (2017). A Study on Decision Support System Based on the Fuzzy Logic Approach for the Livestock Service Management. International Journal of Services, Technology and Management, 23, 83-100. https://doi.org/10.1504/IJSTM.2017.081878

Somasundaram, K., \& Genish, T. (2014). Segmentation of Hippocampus from Human Brain MRI Using Mathematical Morphology and Fuzzy Logic.

Srivastava, S., Pant, M., \& Agrawal, N. (2018). Psychology of Adolescents: A Fuzzy Logic Analysis. International Journal of Systems Assurance Engineering and Management, 9, 66-81. https://doi.org/10.1007/s13198-016-0472-9

Tah, J. H. M., \& Carr, V. (2000). A Proposal for Construction Project Risk Assessment Using Fuzzy Logic. Construction Management and Economics, 18, 491-500. https://doi.org/10.1080/01446190050024905

Vinodh, S., \& Balaji, S. R. (2011). Fuzzy Logic Based Leanness Assessment and Its Decision Support System. International Journal of Production Research, 49, 4027-4041. https://doi.org/10.1080/00207543.2010.492408

Yager, R. R., \& Zadeh, L. A. (2012). An Introduction to Fuzzy Logic Applications in Intelligent Systems (Vol. 165). Berlin: Springer Science \& Business Media. 
Zadeh, L. A. (1994). Fuzzy Logic, Neural Networks, and Soft Computing. Communications of the ACM, 37, 77-84. https://doi.org/10.1145/175247.175255

Zhou, X. S., \& Dong, M. (2004). Can Fuzzy Logic Make Technical Analysis 20/20? Financial Analysts Journal, 60, 54-75. https://doi.org/10.2469/faj.v60.n4.2637

Zohuri, B., \& Moghaddam, M. (2017). Business Resilience System (BRS): Driven through Boolean, Fuzzy Logics and Cloud Computation: Real and near Real Time Analysis and Decision Making System. Berlin: Springer International Publishing.

https://doi.org/10.1007/978-3-319-53417-6 